says study co-author Christina Richey, former chair of the American Astronomical Society's Committee on the Status of Women in Astronomy in Washington DC. The research team was made up of two planetary scientists and two social scientists, including anthropologist Kathryn Clancy of the University of Illinois at Urbana-Champaign, who led a high-profile survey of harassment in scientific fieldwork that was published in 2014 in PLoS ONE (K. B. H. Clancy et al. PLoS ONE 9, e102172; 2014).

The latest study found that harassment and discrimination can have a heavy impact on a person's career decisions. Eighteen per cent of women of colour and $12 \%$ of white women reported avoiding a class, conference or professional event because they did not feel safe attending. Such events can help to foster professional networks, mentorship and opportunities for collaboration - connections that can advance a scientist's career, says Zuleyka Zevallos, a sociologist at Swinburne University of Technology in Melbourne, Australia.

\section{SYSTEMIC SOLUTIONS}

"If a culture of hostility remains in place, it doesn't matter what we do at the individual level because the system is broken. The pipeline is broken," says Zevallos, who helped to implement gender-education programmes at universities in her former position at the Australian Academy of Science in Canberra.

The analysis has sparked intense discussion online among astronomers and planetary scientists. Several female scientists of colour have shared their stories on Twitter, describing the significant, but sometimes subtle, consequences of harassment and discrimination in their own lives.

Chanda Prescod-Weinstein, a theoretical physicist at the University of Washington in Seattle, tweeted that when faced with events that she thought might expose her to harassment, discrimination or other negative experiences, she sometimes brought her husband along. But that created an extra financial burden for the couple.

In recent years, professional societies such as the American Astronomical Society and American Geophysical Union have taken steps to prevent harassment at their meetings. The latest study suggests several actions that research institutions, funding agencies and scientific societies can take to reduce harassment. These include updating their codes of conduct to bar harassment; instituting mandatory cultural-awareness training; encouraging leading researchers to model appropriate behaviour; and putting in place swift sanctions for perpetrators.

"It's time to pivot away from the conversation of, 'Is gender equity and racism a problem in science?', and shift to taking action," Zevallos says. "We can't afford to lose more women of colour, white women and under-represented minorities." -

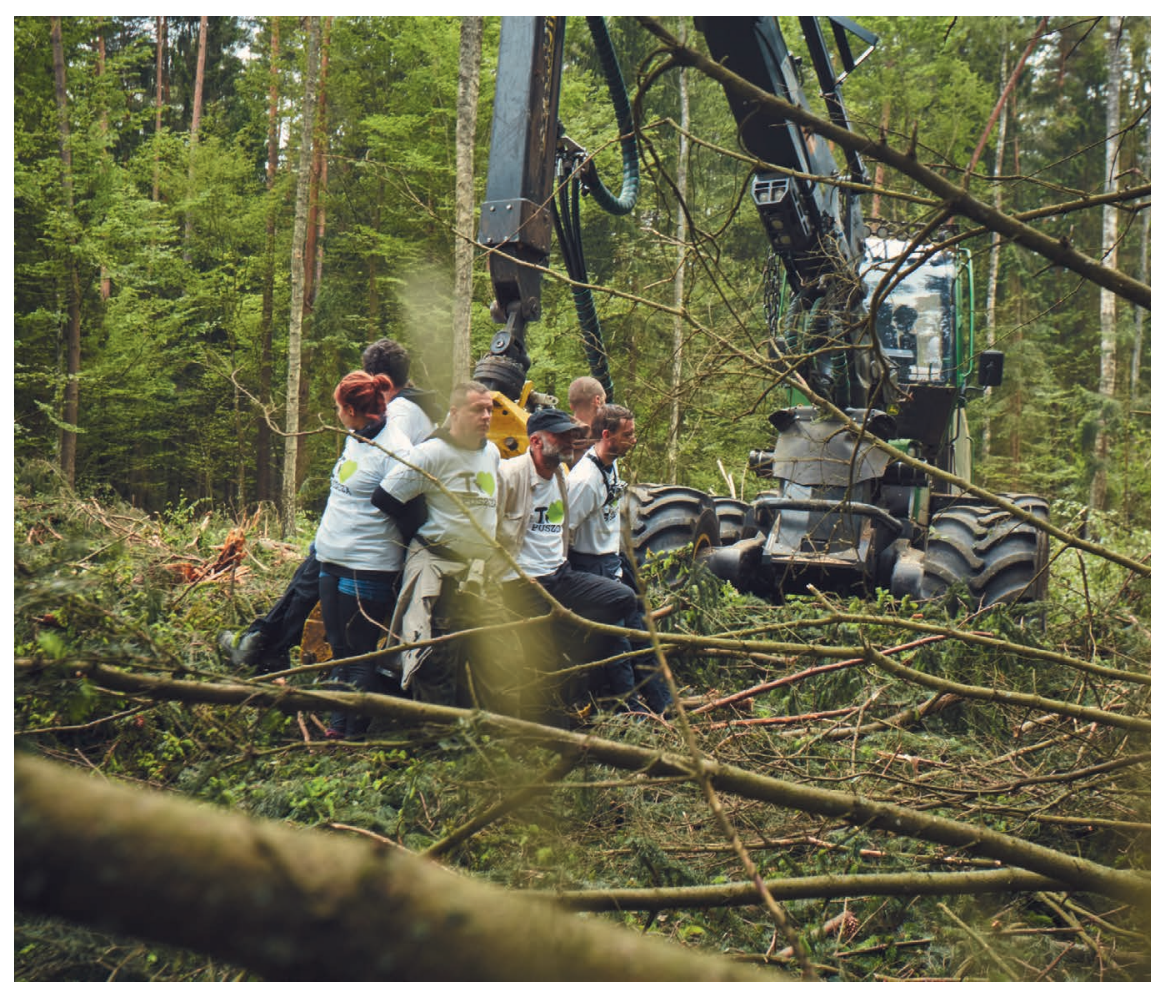

Activists have tried to block logging operations in the Białowieża Forest.

\title{
CONSERVATION
}

\section{Europe fights for ancient forest}

\section{European Commission takes Poland to highest court over policy allowing logging in a biodiversity hotspot.}

\section{BY QUIRIN SCHIERMEIER}

A campaign by scientists and environmental activists to prevent a surge in logging in Europe's ancient Białowieża Forest is headed to the courts.

The European Commission announced on 13 July that it is referring Poland to Europe's highest court after the Polish government declined to roll back controversial new rules that allow more tree-felling in Białowieża - a biodiversity hotspot and the largest remaining patch of a primeval forest that once covered the European Plain. The court case could take years, but the commission has also asked for an immediate ban on logging to prevent further environmental damage.

That's a rare request, says Agata Szafraniuk, a Warsaw-based legal expert with environmental-lawyer group ClientEarth, which is campaigning to protect the forest. The Court of Justice of the European Union (ECJ) has been asked only four times before to impose interim bans on activities that might result in environmental harm - and in all cases, it ordered a halt within days or weeks. (Those instances concerned the illegal hunting of wild birds in Malta and, twice, in Italy; and the building of a highway through protected wetlands in northeast Poland.)

The battle over management of Białowieża - a United Nations World Heritage Site whose roughly 1,500 square kilometres straddle the Poland-Belarus border - has been raging for more than a year. The forest provides habitats for a rich diversity of fungi, insects, birds and mammals, including the largest population of European bison (Bison bonasus), and is also a valuable research resource. Scientists have conducted numerous studies there, most recently into the activity of two bat species (Nyctalus noctula and Nyctalus leisleri) ${ }^{1}$ and the Eurasian lynx $(\operatorname{Lyn} x \operatorname{lyn} x)^{2}$. 
- In March 2016, Poland's environment minister, Jan Szyszko, who is also a forester and entomologist, amended forest-management rules to permit a three-fold increase in timber harvesting from Białowieża. His ministry argues that dead wood needs to be removed to combat an infestation of the European spruce bark beetle (Ips typographus) in the forest's Norway spruce (Picea abies).

But scientists argued against those plans. "Beetle pests are natural processes from which a forest can regenerate without intervention," says Rafał Kowalczyk, director of the Polish Academy of Sciences' Mammal Research Institute in the village of Białowieża. "The current outbreak is severe, but absolutely not dangerous." On 29 April, the 150 participants of an international forest conference in Neuschönau, Germany, wrote a letter to Szyszko, arguing that natural disturbances such as wildfires and insect outbreaks are an inherent part of forest ecosystems. Meanwhile, environmental protesters have taken more extreme action, including chaining themselves to logging machines in protest. Kowalczyk says - as do other opponents of the logging policy - that he suspects the amended forest-management plan is a concession to commercial interests, although the environment ministry says that there are no commercial incentives at play.

\section{COURT WARNINGS}

In June 2016, the European Commission sent a formal notification to Poland's government that the logging amendments risked infringing on EU laws protecting birds and habitats, and urging it to comply. In April this year, it sent a final warning. Poland replied, in a letter not made public. But Kowalczyk thinks it is likely that the country restated its stance that active forest management is necessary to combat the beetle pest, and that the long-term impact of increased logging on forest health would be closely monitored. Regardless, the reply did not satisfy the commission.

It's now up to the ECJ, the final arbiter in EU legal matters, to consider a ban. No country has refused to comply when the ECJ has ordered interim bans to prevent immediate harm, Szafraniuk says. If a ban were ordered and Poland did not obey, the commission could impose daily fines - perhaps as large as hundreds of thousands of euros - or withdraw EU funds.

"We hope that the Court of Justice will impose the ban on logging, as a matter of urgency, before its summer break on 21 July," says Szafraniuk. If it does not, any decision on an interim ban will have to wait until September when the ECJ resumes its work.

1. Ruczyński, I., Zahorowicz, P., Borowik, T. \& Hałat, Z. Mamm. Res. 62, 65-73 (2017)

2. Schmidt, K., Davoli, F., Kowalczyk, R. \& Randi, E. Integr. Zoology 11, 334-349 (2016).

\section{US lawmakers seek extra $\$ 1.1$ billion for the NIH}

\section{Panel rejects plan to cut health-research agency's 'indirect cost' payments to institutions.}

\section{BY LAUREN MORELLO}

$\mathrm{T}$ The US National Institutes of Health (NIH) would see its budget rise by US $\$ 1.1$ billion in 2018 , to $\$ 35.2$ billion, under a spending proposal released on 12 July by lawmakers in the House of Representatives.

The legislation explicitly rejects a plan by the administration of President Donald Trump to cut the NIH's budget by $18 \%$ in 2018 (see 'Funding boost'). The president's proposal would achieve that largely by reducing how much the agency pays to reimburse its grant recipients' institutions for "indirect costs" expenses such as administration and facilities maintenance. Instead, the House bill includes a provision that directs the NIH to compensate institutions for those expenses, although the materials released so far do not include full details of the requirements. On 13 July, the House spending subcommittee that oversees the NIH voted to advance the legislation to consideration by the full appropriations committee.

The NIH spent $\$ 6.3$ billion of its \$30.4-billion budget for 2015 on indirectcost payments. It has long negotiated with individual research institutions to set the rate at which they are reimbursed for overhead

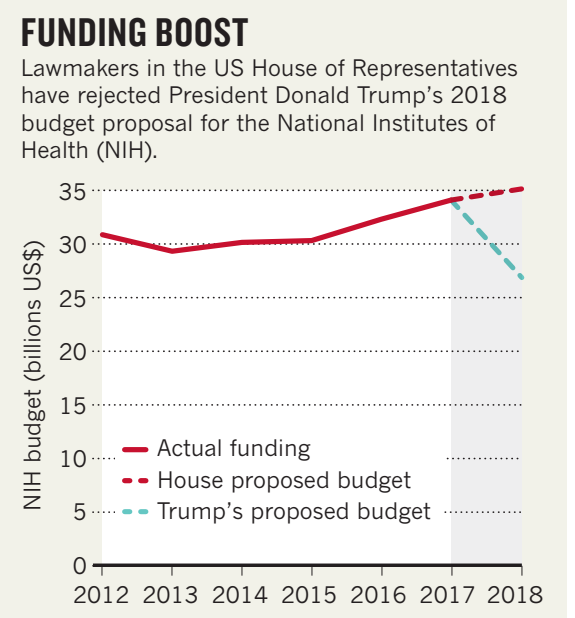

costs. These payments are not deducted from the amount awarded to specific researchers, but are paid separately as a percentage of the grant amount.

A Nature investigation in 2014 found that indirect-cost rates vary from $20 \%$ to $85 \%$ at universities, with an even wider range for hospitals and non-profit institutions. The White House plan had sought to set a uniform rate for these payments, arguing that the change would help to reduce "the risk for fraud and abuse".

The House bill's overall funding for the NIH and its treatment of indirect costs is encourag ing, especially in contrast to the Trump proposal, says Benjamin Corb, director of public affairs at the American Society for Biochemistry and Molecular Biology in Rockville, Maryland. "We are appreciative that the committee recognizes the important role universities play in the research enterprise," he says.

The House legislation also includes increased funding for several high-profile projects in which the NIH is involved. The agency's All of Us research programme, an ambitious study of health records and genomic information from one million people in the United States, would receive $\$ 400$ million, an $\$ 80$-million boost from the 2017 level. And the BRAIN Initiative (Brain Research through Advancing Innovative Neurotechnologies) would receive $\$ 336$ million, an increase of $\$ 76$ million.

The agency's research programmes on Alzheimer's disease would get an extra $\$ 400$ million above the 2017 level, raising their total funding to $\$ 1.8$ billion. However, the budget for the Cancer Moonshot, which seeks to accelerate progress towards cures, would hold steady at $\$ 300$ million. 